\title{
Emergence and characterisation of vanB vancomycin-resistant Enterococcus faecalis in Rio de Janeiro, Brazil
}

\author{
Vânia Lúcia Carreira Merquior ${ }^{1 /+}$, Adriana Rocha Faria ${ }^{1,2}$, Filomena Soares Pereira da Rocha ${ }^{2}$, \\ Jaqueline Martins Morais², Felipe Piedade Gonçalves Neves³, Lúcia Martins Teixeira²
}

1Departamento de Microbiologia, Imunologia e Parasitologia, Faculdade de Ciências Médicas, Universidade do Estado do Rio de Janeiro, Av. Vinte e Oito de Setembro 87/fundos 3o, 20551-030 Rio de Janeiro, RJ, Brasil nstituto de Microbiologia, Universidade Federal do Rio de Janeiro, Rio de Janeiro, RJ, Brasil ${ }^{3}$ Instituto Biomédico, Universidade Federal Fluminense, Niterói, RJ, Brasil

Here we describe the detection and characterisation of three isolates of vancomycin-resistant VanB-type Enterococcus faecalis. Sequence analysis suggested that these isolates harboured the vanB1 gene. The isolates were susceptible to the majority of antimicrobial agents tested, with the exception of chloramphenicol, erythromycin and vancomycin, and showed distinct profiles of high-level resistance to aminoglycosides. Analysis of the clonal relatedness of the vanB E. faecalis isolates showed similar pulsed-field gel electrophoresis profiles. To our knowledge, this is the first report of the occurrence of enterococcal strains carrying vanB genes in Brazil.

Key words: Enterococcus faecalis - vancomycin-resistant Enterococcus - vanB gene

Vancomycin-resistant enterococci (VRE) have become a major cause of nosocomial infections. Glycopeptide resistance in enterococci is genotypically and phenotypically diverse and VanA and VanB types are the two most common classes of acquired resistance. The VanA type is characterised by high-level resistance to both vancomycin and teicoplanin, while the $\operatorname{Van} B$ type is characterised by variable levels of resistance to vancomycin and susceptibility to teicoplanin. In contrast to the VanA type, which is widespread worldwide, the VanB type is much less frequently encountered; however, the VanB type has been detected in human and animal isolates from different countries (McGregor \& Young 2000, Werner et al. 2008, Fang et al. 2010, Johnson et al. 2010), including South America (López et al. 2009). To our knowledge, the VanB type of resistance has not previously been reported among enterococcal isolates from Brazil.

The vanA gene cluster is usually located within transposon $\operatorname{Tn} 1546$ or related elements, while the vanB gene cluster has mostly been associated with $\operatorname{Tn} 1547$ and Tn5382-like transposons (including Tn1549). Based on the sequence diversity of the $\operatorname{van} B$ ligase gene, three subtypes have been described: vanB1, vanB2 and vanB3 (Patel et al. 1998). Epidemiological studies of human clinical isolates from both hospital and community settings indicate a higher prevalence of vanB2 among the vanB subtypes (McGregor \& Young 2000, McGregor et al. 2001, López et al. 2009).

Financial support: CNPq, FAPERJ

+ Corresponding author: vania.merquior@pq.cnpq.br

Received 13 September 2011

Accepted 2 February 2012
The emergence of VRE in Rio de Janeiro (RJ), a state located in the southeastern region of Brazil, was detected in Enterococcus faecalis strains harbouring the van $A$ gene in 2000 (Albuquerque 2001). Since that time, vanA-carrying Enterococcus faecium have become nearly absolutely dominant among VRE, which remains a major cause of concern (Teixeira 2007, Merquior et al. 2010). During ongoing studies in our laboratory, we have detected the emergence of $E$. faecalis strains carrying the $\operatorname{van} B$ gene in patients from two different hospitals. In the present study, we report the characteristics of these first isolates of vanB E. faecalis recovered from clinically significant specimens (Table) obtained from patients living in RJ during the period from 2006-2007. A comparison of these characteristics with those of glycopeptide-resistant (vanA) and/or high-level aminoglycoside-resistant $E$. faecalis clones found in health care institutions in $\mathrm{RJ}$ is also presented.

This study assessed three vancomycin-resistant and teicoplanin-susceptible Enterococcus strains isolated from three patients with severe infections who were hospitalised in two health care institutions in RJ. The isolates were identified using conventional physiological tests, as recommended elsewhere (Teixeira et al. 2011). The isolates were tested regarding the following parameters: pyrrolidonyl arylamidase and leucine aminopeptidase activities, growth and blackening of bile esculin agar, growth in the presence of $6.5 \% \mathrm{NaCl}$, arginine dihydrolase activity, utilisation of pyruvate, acid production from various sugars, such as arabinose, manitol, methyl-a-Dglucopyranoside, raffinose, sorbitol, sorbose and sucrose and with respect to motility and pigment production.

Disk diffusion tests were performed on Müeller-Hinton agar (BD Diagnostic Systems, Franklin Lakes, NJ, USA) according to Clinical and Laboratory Standards Institute guidelines (CLSI 2010). The following antimicrobial agents were tested: ampicillin, chloramphenicol, ciprofloxacin, erythromycin, fosfomycin, gentamicin, 
TABLE

Characteristics of vanB-harbouring Enterococcus faecalis isolates included in the present study

\begin{tabular}{|c|c|c|c|c|c|c|c|c|c|c|c|c|c|c|c|c|c|c|}
\hline \multirow{2}{*}{$\begin{array}{l}\text { Strain } \\
\text { number }\end{array}$} & \multirow{2}{*}{$\begin{array}{l}\text { Patient } \\
\text { number }\end{array}$} & \multirow[b]{2}{*}{ Hospital } & \multirow[b]{2}{*}{ Source } & \multicolumn{13}{|c|}{ Antimicrobial tested/category of susceptibility by agar diffusion tests } & \multicolumn{2}{|c|}{$\begin{array}{c}\mathrm{MIC} \\
(\mu \mathrm{g} / \mathrm{mL})\end{array}$} \\
\hline & & & & AMP & $\mathrm{CHL}$ & CIP & ERY & FOS & LNZ & NIT & NOR & TET & TEI & VAN & GEN & STR & VAN & TEI \\
\hline CL-7320 & 1 & A & Blood & $\mathrm{S}$ & $\mathrm{R}$ & $\mathrm{S}$ & $\mathrm{R}$ & $\mathrm{S}$ & $\mathrm{S}$ & S & S & $\mathrm{S}$ & $\mathrm{S}$ & $\mathrm{R}$ & $\mathrm{R}$ & $\mathrm{R}$ & 64 & 0.38 \\
\hline CL-7785 & 2 & $\mathrm{~B}$ & CSF & S & $\mathrm{R}$ & S & $\mathrm{R}$ & S & S & S & $\mathrm{S}$ & S & $\mathrm{S}$ & $\mathrm{R}$ & $\mathrm{R}$ & $\mathrm{S}$ & 128 & 0.5 \\
\hline CL-7793 & 3 & B & $\mathrm{PF}$ & S & $\mathrm{R}$ & S & $\mathrm{R}$ & $\mathrm{S}$ & S & S & $\mathrm{S}$ & S & $\mathrm{S}$ & $\mathrm{R}$ & $\mathrm{S}$ & $\mathrm{R}$ & 128 & 0.5 \\
\hline
\end{tabular}

AMP: ampicillin; CHL: chloramphenicol; CIP: ciprofloxacin; CSF: cerebrospinal fluid; ERY: erythromycin; FOS: fosfomycin; GEN: gentamicin (high-content disks); LNZ: linezolid; MIC: minimal inhibitory concentration; NIT: nitrofurantoin; NOR: norfloxacin; PF: pleural fluid; R: resistant; S: susceptible; STR: streptomycin (high-content disks); TEI: teicoplanin; TET: tetracycline; VAN: vancomycin.

linezolid, nitrofurantoin, norfloxacin, streptomycin, tetracycline, teicoplanin and vancomycin (Oxoid Ltd, Cambridge, UK). The minimum inhibitory concentrations (MICs) for vancomycin and teicoplanin were determined using the Etest (AB Biodisk, Solna, Sweden).

Polymerase chain reaction (PCR) assays to detect vancomycin resistance genes (vanA and vanB) were performed using primer pairs and amplification conditions previously defined by Clark et al. (1993). Template DNA was prepared with the illustra Bacteria genomicPrep Mini Spin Kit (GE Healthcare Bio-Sciences Corp, Piscataway, NJ). Briefly, each $100 \mu \mathrm{L}$ PCR mixture consisted of $2 \mu \mathrm{L}$ of DNA preparation, $0.5 \mu \mathrm{M}$ each specific primer, $2.5 \mathrm{U}$ of Taq DNA polymerase, $200 \mu \mathrm{M}$ deoxynucleoside triphosphates and $1.5 \mathrm{mM} \mathrm{MgCl}_{2}$. PCR amplifications were carried out via an initial lysis and denaturation step at $95^{\circ} \mathrm{C}$ for $10 \mathrm{~min}$, followed by $30 \mathrm{cy}-$ cles of $94^{\circ} \mathrm{C}$ for $30 \mathrm{~s}, 58^{\circ} \mathrm{C}$ for $30 \mathrm{~s}$ and $72^{\circ} \mathrm{C}$ for $30 \mathrm{~s}$ and a final extension at $72^{\circ} \mathrm{C}$ for $10 \mathrm{~min}$. E. faecalis strain A256 (vanA genotype) and E. faecalis strain V583 (vanB genotype) were used as reference strains.

vanB PCR products were sequenced using the ABI PRISM Big Dye Terminator version 3.1 Ready Reaction Cycle Sequencing Kit (Applied Biosystems by Life Technologies Co, Carlsbad, CA, USA) with an ABI 3130 Genetic Analyzer (Applied Biosystems). The obtained sequences were edited using SeqMan (DNASTAR Inc, Madison, WI) and then subjected to BLAST searches (ncbi.nlm.nih.gov/BLAST/).

Clonal relatedness was determined by pulsed-field gel electrophoresis (PFGE) using a procedure based on previously described recommendations (Teixeira et al. 1997). Briefly, DNA was digested with $20 \mathrm{U}$ of the restriction endonuclease SmaI (New England Biolabs, Beverly, MA) and the fragments were separated in 1.2\% agarose gels using a clamped homogeneous electric field apparatus (CHEF-DRIII system, Bio-Rad Laboratories, Hercules, CA). Electrophoresis was performed for $22 \mathrm{~h}$, with switch times ramping between 5-35 s at $12^{\circ} \mathrm{C}$ with a switch angle of $120^{\circ}$ and an applied voltage gradient of $6 \mathrm{~V} / \mathrm{cm}$. The gels were stained with ethidium bromide and then photographed under ultraviolet light.
Bionumerics software (Applied Maths, Sint-MartensLatem, Belgium) was used for cluster analysis. Percentages of similarity were determined using the Dice correlation coefficient and a dendrogram was produced via the unweighted pair group method with arithmetic mean clustering algorithm.

The bacterial isolates were identified as E. faecalis using conventional physiological tests. The three obtained isolates were resistant to vancomycin, susceptible to teicoplanin and harboured the vanB gene. They were also resistant to chloramphenicol and erythromycin and showed distinct high-level resistance to aminoglycosides [(HLR)-A] profiles (Table). The MICs for vancomycin and teicoplanin, as determined using the Etest, ranged from $64-128 \mu \mathrm{g} / \mathrm{mL}$ and $0.38-0.5 \mu \mathrm{g} / \mathrm{mL}$, respectively.

To further characterise the vanB gene from the three E. faecalis isolates, the obtained $433 \mathrm{bp}$ amplification products were sequenced and then compared to the following reference sequences: vanB1 (GenBank accession U35369), vanB2 (GenBank accessions AF102329.1 and AF310956.2) and vanB3 (GenBank accession U72704). The sequence similarities were examined via BLAST searches, showing 99\% homology with the vanB1 subtype and $96-94 \%$ for vanB2-3. These results suggest that the E. faecalis strains isolated in RJ belonged to the vanB1 subtype (Fig. 1).

Analysis by PFGE revealed that the three $\operatorname{vanB} E$. faecalis isolates showed similar profiles, indicating they belonged to the same clonal group, despite being obtained from patients hospitalised in two different institutions. The dendrogram produced through computer-assisted analysis demonstrated the strong relationship among the PFGE profiles of the $\operatorname{vanB}$ E. faecalis isolates (Fig. 2A). Their profiles were different from PFGE profiles obtained for 10 E. faecalis strains representing clonal groups that have been identified in RJ institutions (Fig. 2B) in previous (Mondino et al. 2003) and ongoing studies by our group. These strains, which were incorporated in the present work for comparative purposes, included vancomycin-susceptible isolates expressing HLR-A, as well as vancomycin-resistant isolates carrying the vanA gene (Fig. 2C). 

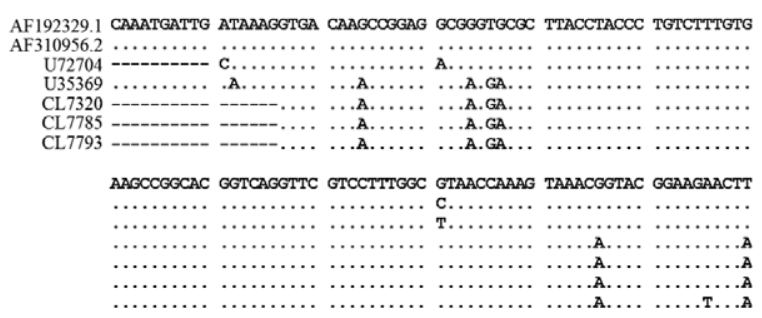

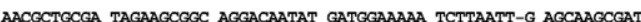

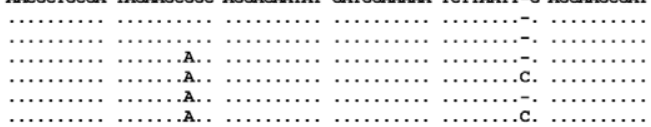

TTCGGGCT-G TGAGGTCGGG T-GTGCGGTC ATGGGGAAOG AGGATGATTT GATT-GTCGG

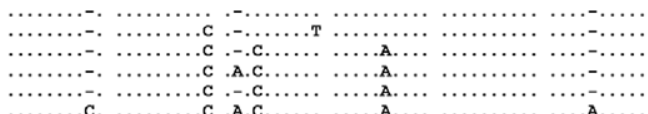

CGAAGTgGat CAAATCCGGC TGAGCCACGg TATCTTCCoC ATCCATCAgG AAAACGAGCC

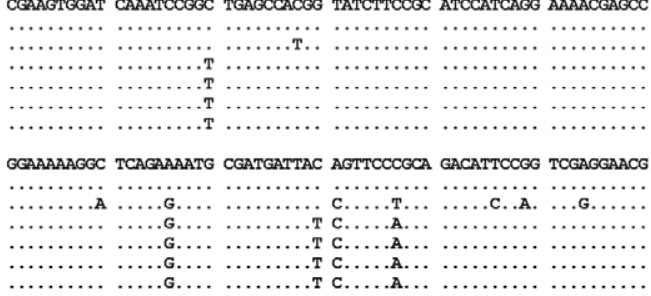

AAATCGGGTG CAGGAAACGG CAAAGAAAGT ATATCGGGTG CTTGGATGCA GAGGGCTTGC

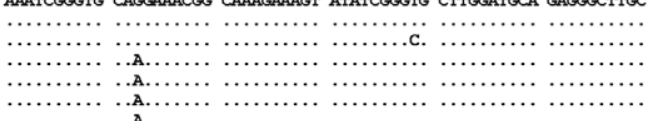

(W.

COGTGTTGAT CTTTPTTTGC AGGAGGATGG CGG

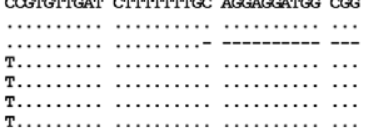

Fig. 1: comparison of vanB sequences from three vancomycin-resistant Enterococcus faecalis isolates from the state of Rio de Janeiro, Brazil. The dots indicate identical sequence and the dashes indicate unavailable sequence. GenBank accessions/genotype: AF102329.1/ vanB2, AF310956.2/vanB2, U72704/vanB3, U35369/vanB1. CL7320, CL7785 and CL7793 E. faecalis strains identified in this study.
Although, the vanA gene is the most common vancomycin resistance determinant associated with VRE isolates presently circulating in Brazil (Pereira et al. 2010), detection of the VanB resistant variant raises concern regarding the possibility of dissemination of this additional VRE genotype in Brazilian institutions.

Similar to the van $A$ gene, the $\operatorname{van} B$ gene cluster is also a significant cause of transferable high-level vancomycin resistance in human clinical enterococci worldwide (McGregor et al. 2001, Werner et al. 2008). However, its origin remains unknown and the mechanisms involved in its intercellular transmission are only partially understood. The major reservoir of acquired van $A$ and $v a n B$ resistance in humans is E. faecium, the prevalence of which has increased over the past 10 years, even though the proportion of vancomycin-resistant $E$. faecalis remains stable in most geographic regions (Werner et al. 2008, Fang et al. 2010). Moreover, vanB has also been described in Enterococcus gallinarum (Mahony et al. 2010), Enterococcus durans (Jenney et al. 2000) and among nonenterococcal reservoirs (Dahl \& Sundsfjord 2003, Domingo et al. 2005).

The detection of clinically significant low-level vancomycin resistance among enterococcal isolates may be challenging. Due to the peculiar inducible characteristics of VanB resistance, MIC values may vary widely among isolates associated with a single outbreak (Pendle et al. 2008). Therefore, routine screening and identification methods are not always reliable for the detection of VRE exhibiting low-level vancomycin resistance. The Health Protection Agency of the United Kingdom has estimated that $25 \%$ of non-VanA enterococci are not detected by diagnostic laboratories (HPA 2004).

In conclusion, we have characterised the first strains of vanB E. faecalis recovered in Brazilian hospitals. Clinicians and microbiologists should be aware of need to promptly detect and characterise this important type of VRE to prevent its dissemination.
A

B

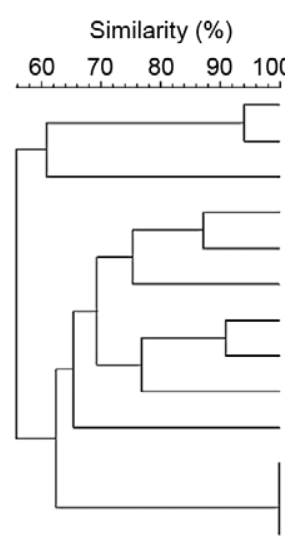

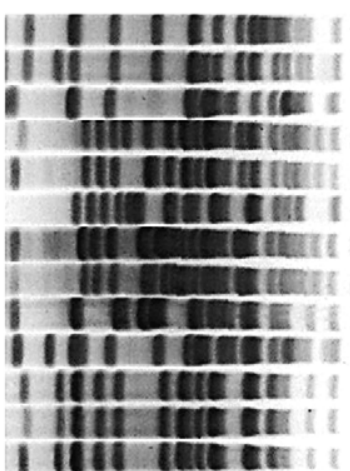

C

\begin{tabular}{lcccc}
\hline & \multicolumn{4}{c}{ Vancomycin } \\
\cline { 2 - 5 } Isolate & GEN & STR & vanA & vanB \\
\hline CL1375 & S & R & - & - \\
CL2991 & S & R & - & - \\
CL2168 & S & S & - & - \\
CL1979 & R & S & - & - \\
CL2101 & R & S & - & - \\
CL2398 & R & R & - & - \\
CL6174 & R & S & + & - \\
CL6703 & R & S & + & - \\
CL5241 & R & S & + & - \\
CL3257 & S & S & - & - \\
CL7320 & R & R & - & + \\
CL7785 & R & S & - & + \\
CL7793 & S & R & - & +
\end{tabular}

Fig. 2: pulsed-field gel electrophoresis (PFGE) profiles of SmaI-digested DNA of Enterococcus faecalis isolates. Dendrogram (A) resulting from automated analysis of chromosomal DNA fragmentation profiles (B) obtained by PFGE and correlation with phenotypic and genotypic resistance (C) patterns. GEN: gentamicin; HLR-A: high-level resistance to aminoglycosides; R: resistant; S: susceptible; STR: streptomycin; -: negative; +: positive. 


\section{REFERENCES}

Albuquerque VS 2001. Enterococos portadores de resistência a níveis elevados de aminoglicosideos: caracterização fenotípica, genotípica e detecção de genes de resistência, MSc Thesis, Universidade do Estado do Rio de Janeiro, Rio de Janeiro, 120 pp.

Clark NC, Cooksey RC, Hill BC, Swenson JM, Tenover FC 1993. Characterization of glycopeptide-resistant enterococci from US hospitals. Antimicrob Agents Chemother 37: 2311-2317.

CLSI - Clinical and Laboratory Standards Institute 2010. Performance standards for antimicrobial susceptibility testing, 20th informational supplement, CLSI M100-S20, Wayne, 153 pp.

Dahl KH, Sundsfjord A 2003. Transferable vanB2 Tn5382-containing elements in fecal streptococcal strains from veal calves. Antimicrob Agents Chemother 44: 2341-2348.

Domingo MC, Huletsky A, Bernal A, Giroux R, Boudreau DK, Picard FJ, Bergeron MG 2005. Characterization of a Tn5382-like transposon containing the vanB2 gene cluster in a Clostridium strain isolated from human faeces. J Antimicrob Chemother 55: 466-474.

Fang H, Nord CE, Ullberg M 2010. Screening for vancomycin-resistant enterococci: results of a survey in Stockholm. Acta Pathol Microbiol Immunol Scand 118: 413-417.

HPA - Health Protection Agency, United Kingdom 2004. National glycopeptide-resistant enterococcal bacteraemia surveillance working group. Report to the Department of Health. August 2004. [updated 2008 Aug 12; cited 2011 Dec 26]. Available from: hpa.org.uk/webc/HPAwebFile/HPAweb_C/1194947322945.

Jenney A, Franklin C, Liolios L, Spelman D 2000. Enterococcus durans VanB. J Antimicrob Chemother 46: 515.

Johnson PD, Ballard SA, Grabsch EA, Stinear TP, Seemann T, Young HL, Grayson ML, Howden BP 2010. A sustained hospital outbreak of vancomycin-resistant Enterococcus faecium bacteremia due to emergence of vanB E. faecium sequence type 203. J Infect Dis 202: 1278-1286.

López M, Hormazábal JC, Maldonado A, Saavedra G, Baquero F, Silva J, Torres C, del Campo R 2009. Clonal dissemination of Enterococcus faecalis ST201 and Enterococcus faecium CC17ST64 containing Tn5382-vanB2 among 16 hospitals in Chile. Clin Microbiol Infect 15: 586-588.

Mahony AA, Huysmans MB, Liolios L, Faull JA, De Boer J, Spelman DW 2010. Emergence of vanB Enterococcus gallinarum colonization in association with glycopeptide therapy. J Clin Microbiol 48: 2319-2320.

McGregor KF, Nolan C, Young HK, Palepou MFI, Tusall L, Woodford N 2001. Prevalence of the vanB2 gene cluster in VanB glycopeptide-resistant enterococci in the United Kingdom and the
Republic of Ireland and its association with a Tn5382-like element. Antimicrob Agents Chemother 45: 367-368.

McGregor KF, Young HK 2000. Identification and characterization of $v a n B 2$ glycopeptide resistance elements in enterococci isolated in Scotland. Antimicrob Agents Chemother 44: 2341-2348.

Merquior VLC, Rocha FSP, Morais JM, Faria AR, Monteiro da Silva BN, Teixeira LD, Teixeira LM 2010. A predominant clonal complex of vancomycin-resistant Enterococcus faecium is associated with the large VRE outbreak in Rio de Janeiro, Brazil. Am J Trop Med Hyg 83 (Suppl.): 307.

Mondino SSB, Castro ACD, Mondino PJJ, Carvalho MGC, Silva KMF, Teixeira LM 2003. Phenotypic and genotypic characterization of clinical and intestinal enterococci isolated from inpatients and outpatients in two Brazilian hospitals. Microb Drug Resist 9: 167-174.

Patel R, Uhl JR, Kohner P, Hopkins MK, Steckelberg JM, Kline B, Cockerill FR III 1998. DNA sequence variation within vanA, vanB, vanC-1 and vanC-2/3 genes of clinical Enterococcus isolates. Antimicrob Agents Chemother 42: 202-205.

Pendle S, Jelfs P, Olma T, Su Y, Gilroy N, Gilbert GL 2008. Difficulties in detection and identification of Enterococcus faecium with low-level inducible resistance to vancomycin during a hospital outbreak. Clin Microbiol Infect 14: 853-857.

Pereira GH, Müller PR, Zanella RC, Lima MJC, Torchio DS, Levin AS 2010. Outbreak of vancomycin-resistant enterococci in a tertiary hospital: the lack of effect of measures directed mainly by surveillance cultures and differences in response between Enterococcus faecium and Enterococcus faecalis. Am J Infect Control 38: 406-409.

Teixeira CD 2007. Estudo de amostras de Enterococcus spp isoladas de pacientes atendidos em quatro hospitais da cidade de Niterói: caracterização fenotípica e genotípica, MSc Thesis, Universidade Federal Fluminense, Niterói, 136 pp.

Teixeira LM, Carvalho MGS, Merquior VLC, Steigerwalt AG, Brenner DJ, Facklam RR 1997. Phenotypic and genotypic characterization of Vagococcus fluvialis including strains isolated from human sources. J Clin Microbiol 35: 2778-2781.

Teixeira LM, Carvalho MGS, Shewmaker PL, Facklam RR 2011. Enterococcus. In J Versalovic, KC Carroll, G Funke, ML Landry, DW Warnock, Manual of clinical microbiology, ASM Press, Washington DC, p. 350-363.

Werner G, Coque TM, Hammerum AM, Hope R, Hryniewicz W, Johnson A, Klare I, Kristinsson KG, Leclercq R, Lester CH, Lillie M, Novais C, Olsson-Lijequist B, Peixe LV, Sadowy E, Simonsen GS, Top J, Vuopio-Varkila J, Willems RJ, Witte W, Woodford N 2008. Emergence and spread of vancomycin-resistance among enterococi in Europe. Eurosurveillance 13: 1-11. 